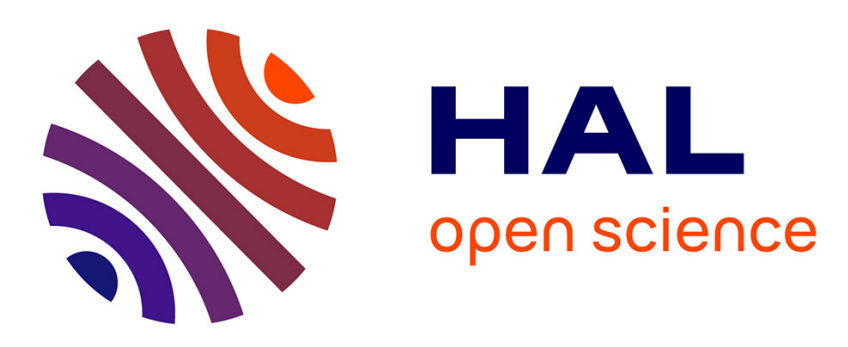

\title{
In vivo osseointegration and erosion of nacre screws in an animal model
}

\author{
Jean-Daniel Kün-Darbois, Hélène Libouban, Georges Camprasse, Serge \\ Camprasse, Daniel Chappard
}

\section{- To cite this version:}

Jean-Daniel Kün-Darbois, Hélène Libouban, Georges Camprasse, Serge Camprasse, Daniel Chappard. In vivo osseointegration and erosion of nacre screws in an animal model. Journal of Biomedical Materials Research Part B: Applied Biomaterials, 2020, 10.1002/jbm.b.34743 . hal-02975091

\section{HAL Id: hal-02975091 \\ https://univ-angers.hal.science/hal-02975091}

Submitted on 22 Oct 2020

HAL is a multi-disciplinary open access archive for the deposit and dissemination of scientific research documents, whether they are published or not. The documents may come from teaching and research institutions in France or abroad, or from public or private research centers.
L'archive ouverte pluridisciplinaire HAL, est destinée au dépôt et à la diffusion de documents scientifiques de niveau recherche, publiés ou non, émanant des établissements d'enseignement et de recherche français ou étrangers, des laboratoires publics ou privés. 


\title{
In vivo osseointegration and erosion of nacre screws in an animal model
}

\author{
Jean-Daniel Kün-Darbois ${ }^{1,2} \odot$ Hélène Libouban ${ }^{1} \quad$ Georges Camprasse $^{3}$ \\ Serge Camprasse ${ }^{3} \quad$ Daniel Chappard $^{1}$
}

\author{
${ }^{1}$ GEROM Groupe d'Etude Remodelage Osseux \\ et bioMatériaux, LHEA, IRIS-IBS Institut de \\ Biologie en Santé, Université d'Angers, CHU \\ d'Angers, Angers Cedex, France \\ ${ }^{2}$ Service de chirurgie maxillo-faciale et \\ stomatologie, CHU d'Angers, Angers Cedex, \\ France \\ ${ }^{3}$ MEGA Bio Pharma, Crosne, France

\section{Correspondence} \\ Jean-Daniel Kün-Darbois, GEROM Groupe \\ d'Etude Remodelage Osseux et bioMatériaux, \\ LHEA, IRIS-IBS Institut de Biologie en Santé, \\ Université d'Angers, CHU d'Angers, 4, rue \\ Larrey, 49933 Angers Cedex, France. \\ Email: jeandaniel.kundarbois@chu-angers.fr
}

\begin{abstract}
The use of resorbable devices for osteosynthesis has become a subject of interest. Nacre has been proposed as a resorbable and osteoconductive material favoring bone apposition without triggering an inflammatory reaction. We compared the in vivo osseointegration and erosion of nacre screws in an animal model with titanium screws. Implantation of similar nacre and titanium screws was performed in the femoral condyles of adult rats. Animals $(n=41)$ were randomized in four groups sacrificed at day one, 1, 6, and 12 months. Microcomputed tomography (microCT) allowed 3D morphometry of erosion of nacre. Osseointegration was measured as the volume of trabecular bone bone volume/tissue volume (BV/TV) in a standardized volume of interest around each screw. Undecalcified bone histology was also done. Gross examination revealed a similar clinical osseointegration for titanium and nacre screws. A progressive erosion of nacre screws, but no erosion of titanium screws, was observed in microCT. The volume of nacre screws progressively decreased over time whereas no modification occurred for titanium. For titanium screws, BV/TV remained stable throughout the study. For nacre screws, the BV/TV decrease was not statistically different. A significant difference was found between nacre and titanium screws at 6 months but not at 12 months. The screw heads, outside the bone shaft, were not eroded even after 12 months. Erosion of nacre occurred during the entire study period, only within the bone shaft in direct contact with bone marrow. Bone apposition was observed on nacre surfaces without signs of erosion. Nacre is a promising biomaterial in maxillofacial surgery.
\end{abstract}

\section{KEYWORDS}

erosion, maxillofacial surgery, mother of pearl, nacre, osseointegration, resorbable device, titanium screw

\section{1 | INTRODUCTION}

Titanium implantable devices are nowadays the gold standard in maxillofacial surgery for osteosynthesis. They have excellent corrosion resistance, mechanical, and osseointegrative properties. ${ }^{1,2}$ Titanium is thus considered as the gold standard biomaterial for osseointegration. ${ }^{3,4}$ Surgical removal of these devices is often necessary after bone consolidation.

The use of resorbable devices (e.g., plates and screws) has consequently become a subject of interest. Furthermore, they allow a progressive transfer of loads to the healing bone in contrast to metallic implants. ${ }^{5}$ Several types of resorbable devices have been evaluated 
TABLE 1 Characteristics of the two types of screws

\begin{tabular}{|lll|}
\hline & Nacre & Titanium \\
\hline Thread length $(\mathrm{mm})$ & 3.36 & 3.90 \\
\hline Diameter of the screw $(\mathrm{mm})$ & 1.63 & 2.09 \\
\hline Number of threads & 8 & 8 \\
\hline Diameter of the screw head $(\mathrm{mm})$ & 4.36 & 4.36 \\
\hline
\end{tabular}

and some are marketed for the current surgical practice. Polylactide, polyglycolide or copolymers are used to prepare screws and plates for maxillofacial surgery. ${ }^{6-8}$ However, these biodegradable polymers do not have the same mechanical properties than titanium and a number of reports have reported local inflammation due to the release of acids during resorption. ${ }^{9,10}$

A number of studies have shown that nacre (also known as mother of pearl), is biocompatible and has good osteoconductive and resorbable properties without triggering a local inflammatory reaction. ${ }^{11-13}$ The use of nacre was recently proposed as a mechanically suitable material with osteoconductive and resorbable properties. ${ }^{13-15}$ Nacre from the giant oyster Pinctada maxima is a natural biomaterial made of calcium carbonate embedded in an organic matter. In scanning electron microscopy, nacre appears composed of flat polygonal tablets of aragonite. This results in a 1000 -folds mechanical strength compared with inorganic crystals. ${ }^{16}$ The oyster shell can be machined to prepare maxillofacial devices with suitable biomechanical properties. Nacre bioerodability can be improved by specific treatments and it precedes bone apposition by osteoblasts. ${ }^{17-19}$ The in vivo resorption is done by macrophage-derived giant cells followed by bone apposition without triggering a local inflammatory reaction. ${ }^{11,12}$

The aim of the present study was to compare the in vivo osseointegration and erosion of nacre versus titanium screws in a rat model at different times using microcomputed tomography (microCT). In the present work, microCT was used to image the changes due to bioerosion and bone formation; the technique allows a 3D quantitative examination of the volume of bone apposed and biomaterial eroded. $^{20}$

\section{2 | MATERIAL AND METHODS}

\subsection{The nacre biomaterial}

Nacre screws were prepared from the inner shell of $P$. maxima coming from an oyster park in Indonesia (Mega BioPharma, Crosne, France). ${ }^{11,15}$ Oysters were approximately $20 \mathrm{~cm}$ in diameter corresponding to a mean age of 7-12 year. Devices were obtained through a process combining physicochemical treatments, machining, and coating operations providing an hybrid semisynthetic material. Titanium screws (TA6V alloy) were provided by the same manufacturer. All devices presented approximately the same size and shape (Table 1). Due to their biological origin, nacre screws presented a
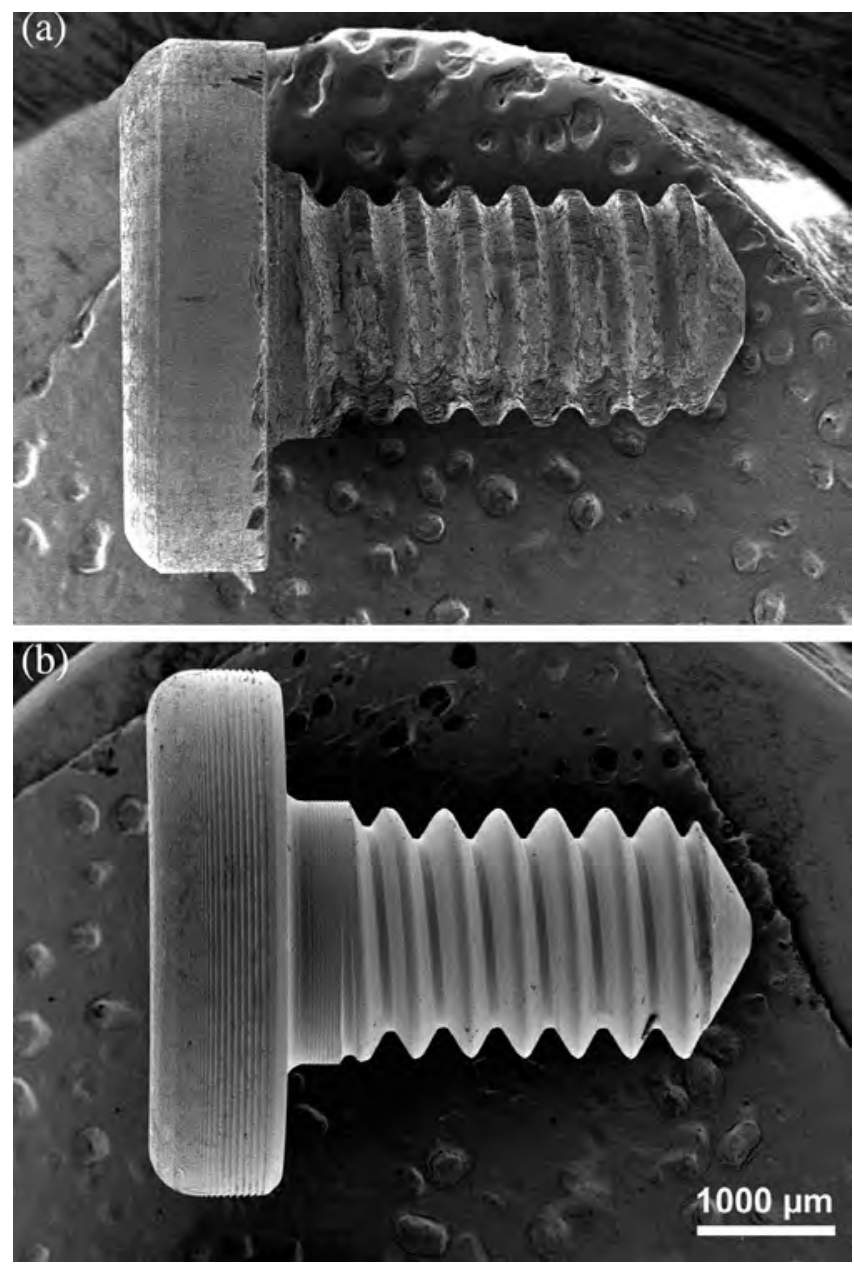

FIGURE 1 Scanning electron microscopy of the two types of screws used in this study. (a) Nacre screw with a rough surface obtained after machining and (b) TA6V titanium screw

rougher surface after machining (Figure 1). All devices were sterilized by $\gamma$ radiation at $25 \mathrm{~Gy}$ and stored until use.

\subsection{Animals and experimental procedure}

All procedures performed in the present study were in accordance with the ethical standards of the institutional and national research committee and with the 1964 Helsinki declaration and its later amendments. This experimental protocol was approved by the local ethical committee of Angers University Hospital (France) and was done in accordance with the institutional guidelines of the French Ethical Committee (protocol number APAFIS\#2851), the European Community Council Directive of November 24, 1986 (86/609/EEC) and under the supervision of authorized investigators.

Male Sprague-Dawley rats ( $n=41$ ), aged $19 \pm 0.5$ weeks-old, weighing $518.3 \pm 11.5 \mathrm{~g}$, were used for the study (Janvier-Labs, Le Genest-Saint-Isle, France). They were acclimated for 2 weeks to the local vivarium conditions ( $24^{\circ} \mathrm{C}$ and $12 / 12 \mathrm{hr}$ light dark cycle). They were given a standard laboratory food (UAR, Villemoison-sur-Orge, 
France) and water ad libitum. Rats were randomized into four groups T0 ( $n=8)$, T1 ( $=11)$, T6 $(n=11)$, and T12 ( $=11)$.

Screw implantation was performed in all rats under general anesthesia using the same surgical procedure by a trained surgeon. General anesthesia was induced by intraperitoneal injection of $100 \mathrm{mg} / \mathrm{kg}$ ketamine (Renaudin, Aïnhoa, France) and $10 \mathrm{mg} / \mathrm{kg}$ xylazine (Rompun $2 \%$, Bayer, Leverkusen, Germany). Analgesia was obtained using subcutaneous injections of buprenorphine (Vetergesic, Sogeval, Laval, France) at a dose of $0.03 \mathrm{mg} / \mathrm{kg}$, half an hour before surgical procedure and during postoperative monitoring if needed. The femoral condyles were exposed with a lateral approach on right and left sides. Holes adapted to the size of the screws were made using a surgical drill under constant irrigation (sterile saline solution). Screws were then implanted in the drilled holes with a specific screwdriver provided by the manufacturer. For each animal, the nacre screw was placed in the right condyle and the control titanium screw in the left condyle. Each incision was then closed using skin staples. No additional drug and no antibiotic was given. Rats were closely monitored until awakening. A close and regular monitoring was performed twice a day for every rats during the first postoperative week in order to check for clinical signs of pain. Rats were then monitored and weighted monthly and sacrificed by $\mathrm{CO}_{2}$ inhalation at day one (group T0), 1 (group T1), 6 (group T6) and 12 months (group T12). Gross examination was performed to assess clinical osseointegration and to seek for local complications. Femoral condyles were then dissected, defleshed, and fixed in formalin until use.

\section{3 | Microcomputed tomography}

MicroCT of the right femoral condyles (containing nacre screws) was performed using a Skyscan 1,172 X-ray computerized microtomograph (Bruker microCT, Kontich, Belgium) equipped with an $\mathrm{X}$ ray tube working at $70 \mathrm{kV} / 142 \mu \mathrm{A}$. Bones were placed in an Eppendorf's tube filled with water to prevent desiccation. The tube was fixed on a brass stub with plasticine. Analysis was done with a pixel size corresponding to $10.3 \mu \mathrm{m}$; the rotation step was fixed at $0.2^{\circ}$ and exposure was done with a $0.5 \mathrm{~mm}$ aluminum filter. For each sample, a stack of 2D-sections (.jpg format) was obtained, reconstructed using NRecon software (Bruker) and the morphometric analysis was done with the CTAn software (Bruker, release 1.13.11.0). Three-dimensional reconstructions were obtained using CTVox software (Bruker, release 2.5).

The fixed left condyles with the titanium screws could not be imaged with the Skyscan microCT due to the reconstruction artifacts with the metal implants. A microCT with polychromatic X-rays was used to limit these artifacts (Nanotom, Phoenix, GE). Bones were positioned and immobilized in gelatin before acquisition. Analysis was done at $160 \mathrm{kV} / 50 \mu \mathrm{A}$ with a copper filter. Five projection images were averaged every $500 \mathrm{~ms}$, the rotation angle was set at $1.95^{\circ} / \mathrm{min}$ with a pixel size of $0.7 \mu \mathrm{m}$. Image reconstruction was done on the projection images with the DATOS software (Phoenix), and a stack of 2D sections was obtained for each specimen that were exported in the . jpg format to allow analysis with the same software than above.

\subsection{Erosion analysis in 3D}

For each sample, the degree of erosion of the screw was quantified using the CTan software on the stacks of images provided by the two microCT systems. The screw volume (SV, in $\mathrm{mm}^{3}$ ) was determined after thresholding allowing a clear separation of the biomaterial from bone due to the increase calcium content of nacre. The measures were determined on the threads and the screw head (outside the bone shaft) was not considered.

\subsection{Osseointegration analysis}

For each sample, the parameters were determined with the CTan software on the same stacks of images and only on the threads, as defined above. The volume of interest was defined as the fraction of the tissue volume occupied by trabecular bone in a standardized volume of interest automatically generated around each screw with 30 dilatations of the screw image. Briefly, on transverse sections, a ring was computed around the screw according to the manufacturer recommendation (Bruker Academy, 2015 \#3 https://www.bruker.com/products/ microtomography/academy/academy.html). The trabecular bone volume (BV/TV, in \%) was measured in the volume of interest; the standardized nomenclature for bone histomorphometry of the ASBMR was used. $^{21}$

\subsection{Histological analysis}

The bone samples were then embedded in poly(methylmethacrylate) (pMMA) for histological analysis and fluorescence microscopy as previously described. ${ }^{22}$ Blocks embedded in pMMA were then sectioned with a diamond saw (Accutom, Struers, France) in $500 \mu \mathrm{m}$ thick slices. Slices passing through the central zone of the screws were selected and polished on an automatic polishing machine (Struers) to a $1 \mu \mathrm{m}$ finish with diamond particles. Then, surface staining was done after acid etching with $0.1 \%$ formic acid in distilled water for 4 min followed by staining with borax-toluidine blue during $45 \mathrm{~min}$. Slices were dried and analyzed on an Olympus BX 51 microscope and microphotographs were acquired on a DP71 color digital CCD camera.

\subsection{Statistical analysis}

Statistical analysis was performed using the Systat statistical software release 13.0 (Systat Software Inc., San José, CA). All data were expressed as mean \pm SEM. Differences among groups were analyzed by a nonparametric ANOVA (Kruskall-Wallis) followed by a DwassSteel-Chritchlow-Fligner test. Differences between groups at each 

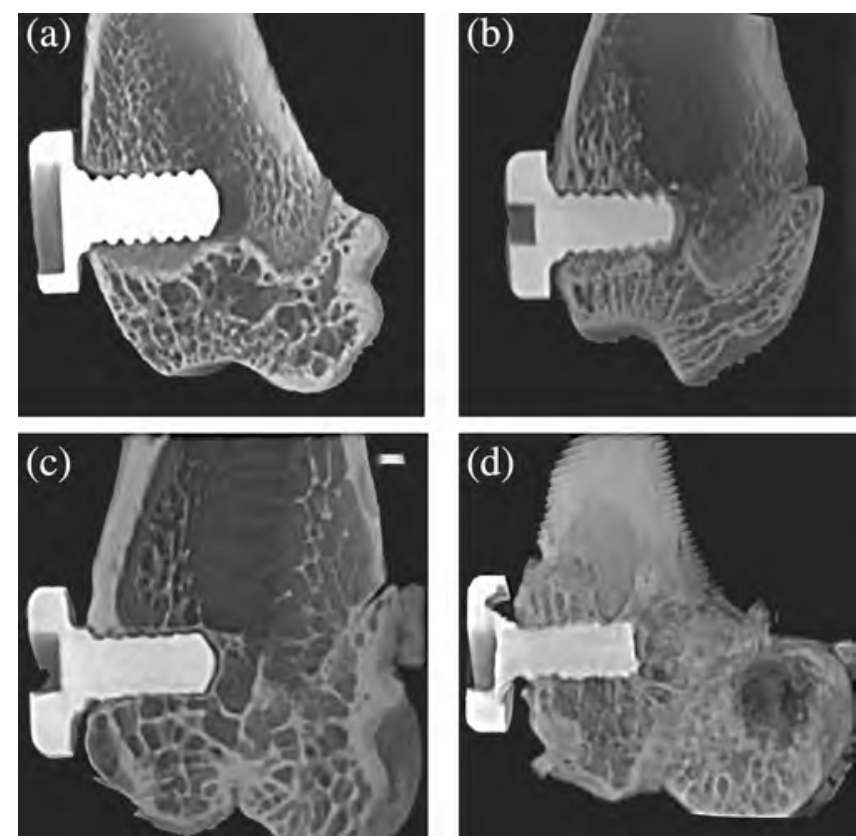

FIGURE 2 Microcomputed tomography 2D images showing nacre screws implanted in the femoral condyle of the rat sacrificed at (a) T0, (b) T1 month, (c) T6 months and (d) T12 months. Note the progressive erosion of nacre screws over time: the height of the threads is progressively reduced. No sign of erosion is observed on screw heads. Also, note the progressive apposition of bone on the biomaterial

time interval were analyzed by a nonparametric Mann and Whitney test. Differences were considered significant when $p<.05$.

\section{3 | RESULTS}

\subsection{Animals and body weight}

One rat was excluded during the study and sacrificed because of unexplained weight loss (group T1). Two animals presented minor transient complications (limping and postoperative hematoma) and were not excluded from the study. All rats regularly gained weight during the study period. No statistical difference was found between groups for weight at any time.

\section{2 | Gross examination}

Only one rat (group T6) presented a mobile nacre screw that was clinically not osseointegrated. In four rats out of 41 (9.75\%) (One rat in group T1 and three in group T6) the head of the nacre screw presented an extra osseous foreign-body reaction made of fibrotic tissue. One rat (group T12) presented a degenerative aspect of the articular cartilage above the titanium screw (abrasion of the articular surface). Every other titanium and nacre screws were clinically osseointegrated without macroscopic signs of any complication.
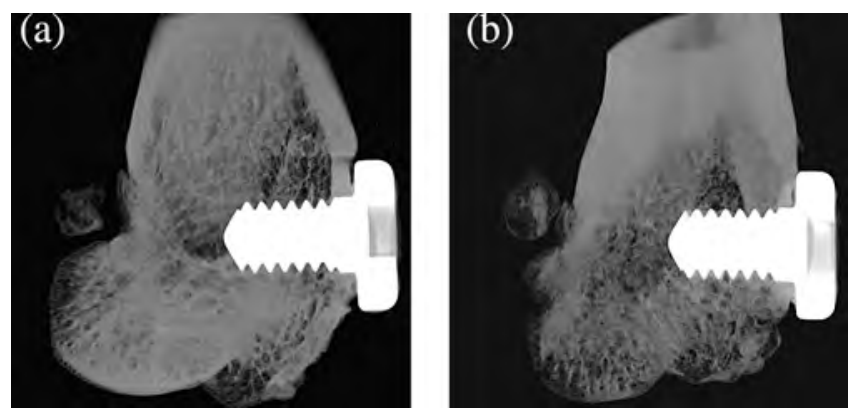

FIGURE 3 Microcomputed tomography 2D images showing titanium screws implanted in femoral condyles at sacrifice at (a) TO and (b) T12. No erosion is seen over time

TABLE 2 Erosion and osseointegration results

\begin{tabular}{|c|c|c|c|}
\hline \multirow[b]{2}{*}{ Biomaterial } & \multirow[b]{2}{*}{ Groups } & \multirow{2}{*}{$\begin{array}{l}\text { Erosion } \\
\\
\text { Screw volume } \\
\left(\mathrm{SV}, \mathrm{mm}^{3}\right)\end{array}$} & \multirow{2}{*}{$\begin{array}{l}\text { Osseointegration } \\
\text { Bone volume/tissue } \\
\text { volume } \\
\text { around screws } \\
\text { (BV/TV, \%) }\end{array}$} \\
\hline & & & \\
\hline \multirow[t]{4}{*}{ Nacre } & TO & $7.07 \pm 0.30$ & $41.26 \pm 23.10$ \\
\hline & $\mathrm{T} 1$ & $7.22 \pm 0.43$ & $40.21 \pm 9.42$ \\
\hline & T6 & $6.19 \pm 0.60$ & $27.85 \pm 11.98$ \\
\hline & $\mathrm{T} 12$ & $3.85 \pm 0.95$ & $26.67 \pm 3.89$ \\
\hline \multirow[t]{4}{*}{ Titanium } & TO & $6.91 \pm 0.91$ & $38.97 \pm 9.78$ \\
\hline & T1 & $7.07 \pm 0.42$ & $41.87 \pm 22.09$ \\
\hline & T6 & $7.04 \pm 0.39$ & $46.63 \pm 14.87$ \\
\hline & T12 & $7.04 \pm 0.55$ & $36.03 \pm 13.33$ \\
\hline
\end{tabular}

Note: Gray boxes indicate a significant difference nacre versus titanium.

\subsection{Erosion of the screws}

3D models obtained by microCT showed a progressive erosion of nacre screws along time with a progressive erosion of threads (but no erosion of screw heads) (Figure 2). As expected, no erosion was found for titanium screws along time (Figure 3).

Quantitative analysis of erosion and osseointegration parameters is summarized in Table 2. SV of nacre screws progressively decreased over time whereas no modification occurred for titanium screws for these parameters and SV remained unchanged (Figure 4a).

\section{4 | Osseointegration analysis}

The 3D models of the inserted screws appear on Figures 5 and 6 . The amount of bone formed around the threads (in the volume of interest) is figured with pseudo-colors. No difference was found for BV/TV at TO between both types of screw. It indicates that the amount of bone around nacre and titanium screws was the same after screw implantation.

For the titanium screws, BV/TV remained stable all along the study (Figure 4b). For the nacre screws, BV/TV seemed to decrease 
(a)

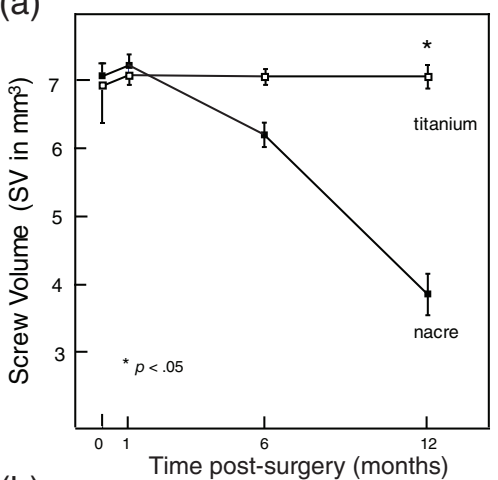

(b)

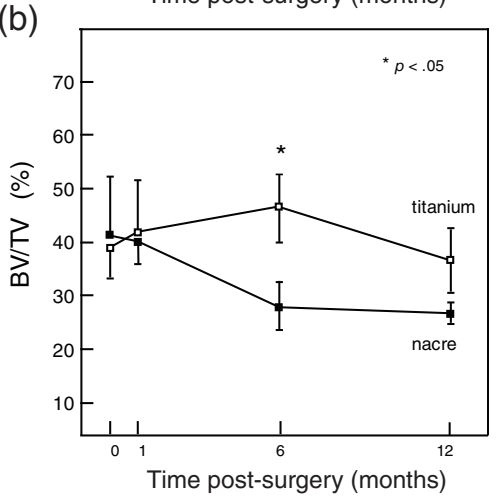

FIGURE 4 Graphs showing evolution of (a) screw volumes and (b) BV/TV for titanium ( $\square$ ) and nacre screws ( $\square$ ). BV/TV, bone volume/tissue volume
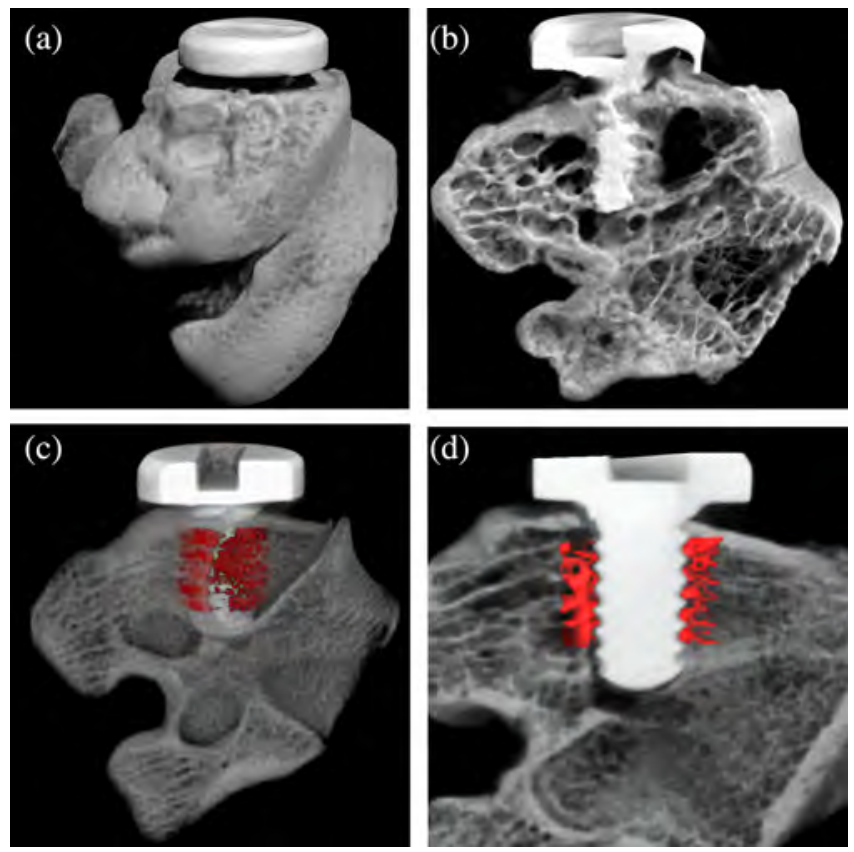

FIGURE 5 Images obtained by microcomputed tomography of a nacre screw implanted in a rat femoral condyle. (a) 3D external view; (b) 3D internal view showing a screw inside trabecular bone; (c) 3D internal view showing a screw and its surrounding trabecular bone formed bone formed inside a hollow cylinder around (figured in red pseudo-color); (d) 2D section showing a screw and the surrounding newly formed trabecular bone (figured in red pseudo-color)
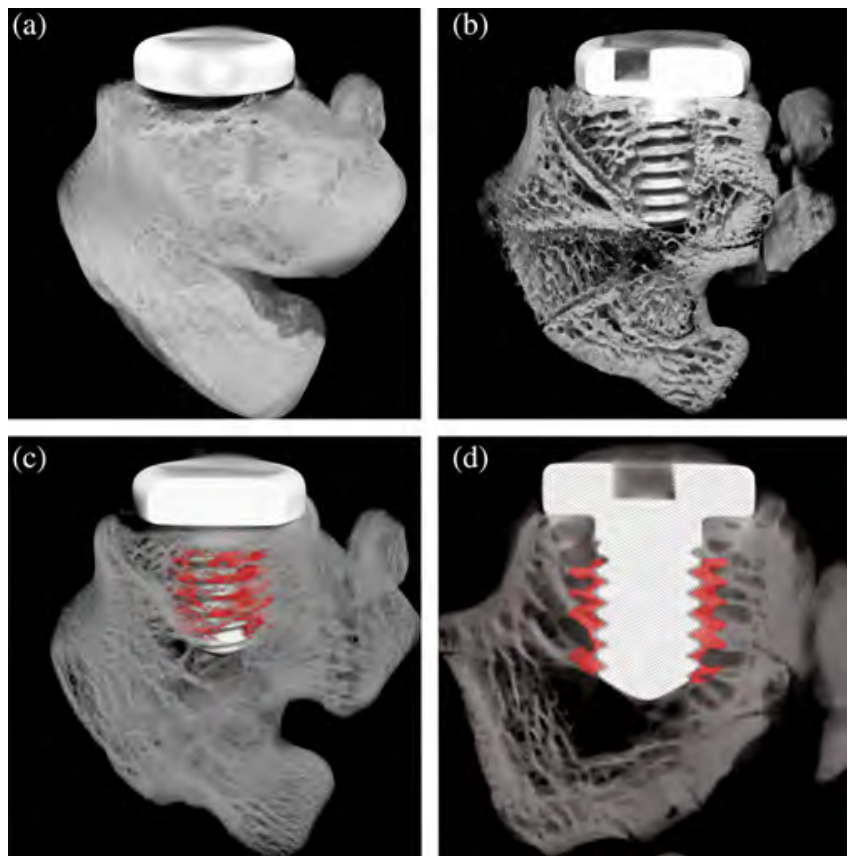

FIGURE 6 Images obtained by microcomputed tomography showing a titanium screw implanted in a rat femoral condyle. (a) 3D external view; (b) 3D internal view showing a screw inside trabecular bone; (c) 3D internal view showing a screw and its surrounding trabecular bone formed inside a hollow cylinder around (figured in red pseudo-color); (d) 2D section showing a screw and the surrounding newly formed trabecular bone (figured in red pseudo-color)

progressively, however, the ANOVA did not found any statistical difference. A significant difference was found only between nacre and titanium screws at T6 $(p=.02)$, however, the difference at T12 did not reach significance.

\subsection{Histological analysis of erosion and osseointegration}

On histological sections, the nacre screws showed a progressive reduction of the thread height in the intraosseous zone, in direct contact with the bone marrow (Figure 7a,b). Numerous images of resorption of the biomaterial by giant cells were clearly evidenced (Figure 7c). At 6 months, resorption of the screw threads within the medullary cavity was clearly evidenced. However, no zone of resorption was visible on the screw head, located in the extra-osseous area (Figure 7d). At 12 months, the aspects were identical and resorption by giant cells was still present with resorption of nacre threads in the intraosseous location appearing more marked. On sections of the condyles containing titanium screws, as expected, no modification of the shape of the threads was noted (Figure 8a,b).

On histological sections, bone was stained in varieties of blue by toluidine blue and nacre had a grayish tint. The most recently apposed bone structure units were more heavily stained, as classically 
(a)
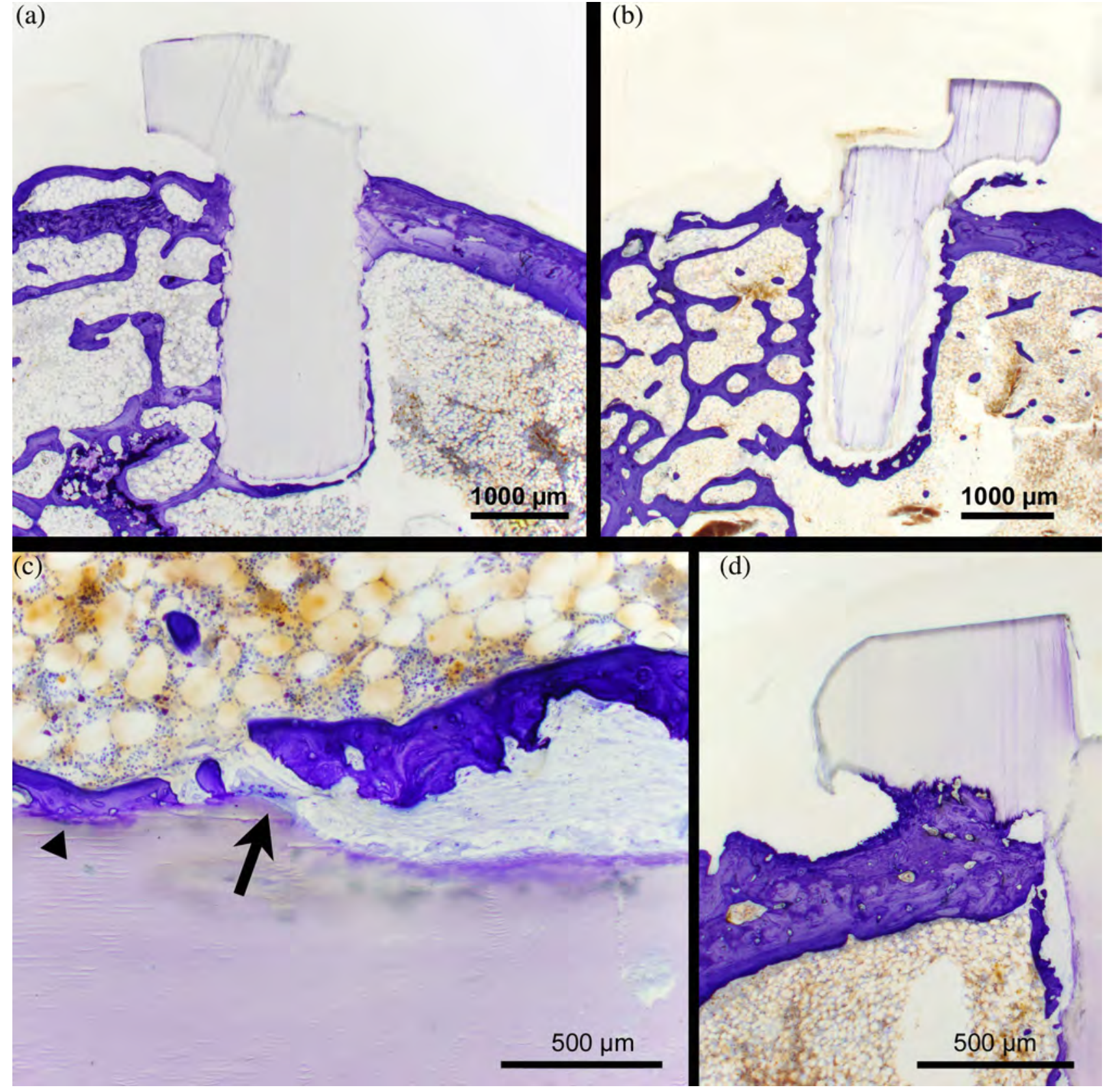

FIGURE 7 Histologic sections of nacre screws implanted in the rat. (a) At 6 months, note the beginning of erosion occurring at the threads but not on the screw head that still has sharply defined contours. Note the simultaneous apposition of bone onto the biomaterial. (b) At 12 months, erosion of the threads inside the marrow cavity is more pronounced and osseointegration is evidenced. Here again, note the absence of signs of resorption at the screw heads. (c) Simultaneous areas of nacre erosion by giant cells (arrow) and direct apposition on the biomaterial (arrowhead). (d) Enlargement of a screw head 12 months after implantation. There is no sign of erosion outside the bone shaft; note the anchoring of the screw in the cortical bone by direct apposition. Surface staining by toluidine blue of polished slabs, the brown areas correspond to blood vessels, located deeper, and superimposed on the image obtained with bright field microscopy

reported. Bone was directly anchored on the surface of the nacre screws in areas that were not undergoing resorption by giant cells (Figure 7). These aspects of conjoined bone apposition and resorption were also well visualized in the trans-cortical passage of the screw. On sections of the condyles containing titanium screws, the apposition of bone to the metal surface was also clearly visible without fibrous interposition between the metal and bone (Figure 8c,d).

\section{4 | DISCUSSION}

In the present work, microCT was used to image the changes due to bioerosion and bone formation; the technique allows a 3D quantitative examination of the volume of bone apposed and biomaterial eroded; this method is more accurate than $2 \mathrm{D}$ histomorphometric analysis. ${ }^{20} \mathrm{~A}$ progressive erosion of nacre screws was evidenced in 
FIGURE 8 Histologic sections of titanium screws implanted in the rat. (a) At 6 months, note the apposition of bone onto the biomaterial. (b) At 12 months, the aspect is similar. (c and d) Enlargement of a screw threads covered with bone at resp. 6 and 12 months after implantation. Surface staining by toluidine blue of polished slabs, the brown areas correspond to blood vessels, located deeper, and superimposed on the image obtained with bright field microscopy

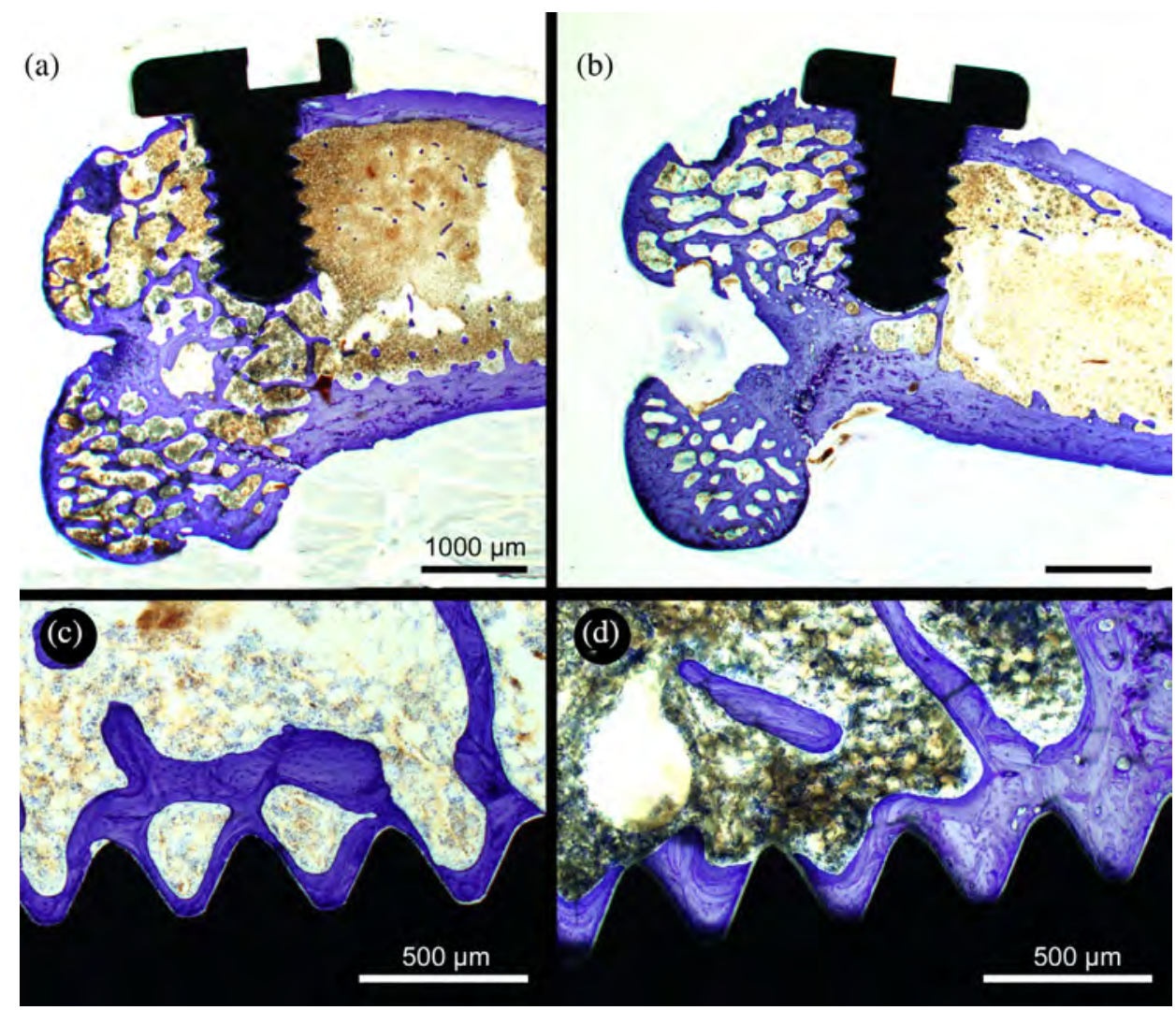

their intraosseous portion (screw threads) but not at their extraosseous portion (screw head). The volume of nacre screws progressively decreased with time showing an in vivo incomplete resorbability in this short-term study. This gradual progressive erosion of nacre screws is in line with previous studies performed with orthopedic screws in the sheep. ${ }^{11}$

The titanium alloy TA6V is widely used nowadays because of its excellent osseointegrative properties and is thus considered as the gold standard biomaterial for osseointegration. ${ }^{1-4}$ A number of studies have shown that nacre is biocompatible and has good osteoconductive and resorbable properties without triggering a local inflammatory reaction. ${ }^{11-13}$

A key finding of the present study was that erosion of nacre screws occurred only during their intraosseous course, in contact with the bone marrow; on the contrary, no erosion was observed at the screw heads. This corresponded clinically with a significant rate of foreign-body reaction surrounding nacre screws heads (9.75\%) in the present work. On the contrary, no foreign-body reaction was observed around the heads of titanium screws. Foreign-body reaction around nacre implants had not been previously described in in vivo studies as these papers mainly focused on the bone-nacre interface $^{11,13,23}$ However, when implanted in muscular pouches in the back muscles of the rat, nacre from the freshwater pearl mussel Margaritifera induced a foreign-body reaction with giant cells but not when they were implanted inside bone. ${ }^{24} \mathrm{~A}$ peculiar myeloid population of intraosseous macrophages has been recently described and called "osteal macrophages" or "osteomacs." ${ }^{25-28}$ These cells are involved in regulating bone homeostasis and seem to have an important phagocytic role. ${ }^{27}$ In a previous study, we showed that nacre, implanted in bone, was only resorbed by giant cells that differed from osteoclasts by cytological and nuclear criteria. ${ }^{12}$ Therefore, the intraosseous resorption of nacre could be performed only by giant cells deriving from "osteal macrophages."

In the present study, BV/TV was used to measure osseointegration by using a hollow cylindrical volume, automatically drawn around the screws. This permitted a direct 3D measurement of the newly formed bone in direct contact with the screws. This 3D method is known to be more precise than measuring this bone/biomaterial interface on $2 \mathrm{D}$ histological sections. A decrease in BV/TV between 6 and 12 months was observed in the titanium group. It could be due to an age-related bone loss and not to an altered osseointegration or increased resorption. It is well known that bone remodeling decreases with age leading to a progressive bone loss. Histomorphometrists have shown that it can be evidenced on bone specimens by a decrease of BV/TV associated with a reduction of bone-forming parameters measured after double tetracycline labeling. ${ }^{29,30}$ Such a bone loss and altered remodeling has already been evidenced in aged rats ${ }^{31}$ and can influence bone healing after the graft of a biomaterial. ${ }^{32}$

Clinical interest in maxillofacial surgery of nacre as a biomaterial needs further investigations. Nacre has excellent structural and mechanical properties. ${ }^{33-36}$ However, we found that these nacre devices were fragile and easily breakable during handling making them unsuitable for osteosynthesis in form of small plates or screws. Usually, the management of facial fractures requires rigid and firm fixation 
to avoid the risks of secondary displacement and plate breaking. In a recent meta-analysis, no statistical differences in the outcome was noted for patients with mandible fractures osteo-synthesized with resorbable or metallic implants. ${ }^{8}$ However, in their article, there was no study comparing the mechanical properties of titanium vs nacre. The brittleness and friability of the surfaces of this biomaterial are clearly visible in Figure 1a, which shows that certain areas of the screws (e.g., the tops of the threads) are torn off during machining depending on the orientation of the aragonite plates. In future studies, we plan to conduct extensive biomechanical tests to determine the compressive and torsional strength of mother-of-pearl screws. In this study, the screws were small in diameter $(1.63 \mathrm{~mm})$ and some fractures were obtained during screwing. This had not occurred when using larger diameter $(3.5 \mathrm{~mm})$ orthopedic screws made of the same biomaterial in a previous study. ${ }^{11}$ Nacre could play a role in preimplant surgery. Nacre screws, since they are partially resorbable, could be used in preimplant bone grafting surgery for osteosynthesis. Currently, titanium screws are indeed used for that purpose and they need to be surgically removed before placing the implant. The use of such nacre screws would spare the surgical removal of titanium screws. It could be interesting in some bone graft reconstruction techniques. ${ }^{37}$ Nacre could also be used as a bone graft substitute in maxillofacial surgery (for maxillary sinus floor elevation for example) and also for orthopedic purposes. ${ }^{13}$

\section{5 | CONCLUSION}

Nacre is a promising biomaterial in maxillofacial surgery but its indications and uses must be carefully discussed, as it appears resorbable only when in contact with the bone marrow and have interesting osseointegration properties. Furthermore, nacre does not lead to an inflammatory reaction, unlike biodegradable polymers and it could be used as a bone graft substitute. It could also serve as a resorbable material for osteosynhesis (e.g., preimplant bone grafting), sparing the surgical removal of the device after bone consolidation.

\section{ACKNOWLEDGMENTS}

The authors thank Mrs. N. Retailleau and S. Lemière for microCT and Mrs. F. Pascaretti for histotechnological help. Authors are greatly indebted to the SCAHU (Service Commun d'Animalerie HospitaloUniversitaire) of Angers, especially to P. Legras and J. Roux for their help with the animal care.

\section{CONFLICT OF INTEREST}

Georges and Serge Camprasse are scientific cooperators at Mega BioPharma.

\section{AUTHOR CONTRIBUTIONS}

Jean-Daniel Kün-Darbois designed the study, performed animal handling, surgical procedures (screw implantations), and microCT analysis and wrote the article. Hélène Libouban performed animal handling and helped to design the study. Georges Camprasse and Serge
Camprasse helped to design the study. Daniel Chappard conceptualized the study, performed microCT and histological analyses and wrote parts of the manuscript.

\section{ORCID}

Jean-Daniel Kün-Darbois (D) https://orcid.org/0000-0002-0818-7856

Daniel Chappard (D) https://orcid.org/0000-0002-5886-9513

\section{REFERENCES}

1. Albrektsson $\mathrm{T}$, Brånemark $\mathrm{P}-\mathrm{I}$, Hansson $\mathrm{H}-\mathrm{A}$, Lindström J. Osseointegrated titanium implants: requirements for ensuring a longlasting, direct bone-to-implant anchorage in man. Acta Orthopaedica Scandinavica. 1981;52:155-170.

2. Wennerberg A, Albrektsson T, Andersson B. An animal study of $\mathrm{cp}$ titanium screws with different surface topographies. J Mater Sci: Mater Med. 1995;6:302-309.

3. Rony L, Lancigu R, Hubert L. Intraosseous metal implants in orthopedics: a review. Morphologie. 2018;102:231-242.

4. Brånemark R, Brånemark $P$, Rydevik $B$, Myers RR. Osseointegration in skeletal reconstruction and rehabilitation: a review. J Rehab Res Develop. 2001;38:175-182.

5. Middleton JC, Tipton AJ. Synthetic biodegradable polymers as orthopedic devices. Biomaterials. 2000;21:2335-2346.

6. Bohner M. Resorbable biomaterials as bone graft substitutes. Mater Today. 2010;13:24-30.

7. Agarwal S, Gupta A, Grevious M, Reid RR. Use of resorbable implants for mandibular fixation: a systematic review. J Craniofacial Surg. 2009; 20:331-339.

8. Chocron Y, Azzi AJ, Cugno S. Resorbable implants for mandibular fracture fixation: a systematic review and meta-analysis. Plast Reconstr Surg-Global Open. 2019;7:e2384.

9. Böstman OM, Pihlajamäki HK. Adverse tissue reactions to bioabsorbable fixation devices. Clin Orthop Relat Res. 2000;371:216-227.

10. Aristizabal AFC, Sanders EJ, Barber FA. Adverse events associated with biodegradable lactide-containing suture anchors. Arthroscopy. 2014;30:555-560.

11. Libouban H, Pascaretti-Grizon F, Camprasse G, Camprasse S, Chappard D. In vivo erosion of orthopedic screws prepared from nacre (mother of pearl). Orthop Traumatol: Surg Res. 2016;102: 913-918.

12. Chappard D, Kun-Darbois JD, Pascaretti-Grizon F, Camprasse G, Camprasse S. Giant cells and osteoclasts present in bone grafted with nacre differ by nuclear cytometry evaluated by texture analysis. J Mater Sci: Mater Med. 2019;30:100.

13. Zhang G, Brion A, Willemin AS, et al. Nacre, a natural, multi-use, and timely biomaterial for bone graft substitution. J Biomed Mater Res-A. 2017;105:662-671.

14. Mouries LP, Almeida MJ, Milet C, Berland S, Lopez E. Bioactivity of nacre water-soluble organic matrix from the bivalve mollusk Pinctada maxima in three mammalian cell types: fibroblasts, bone marrow stromal cells and osteoblasts. Comp Biochem Physiol Part B, Biochem Mol Biol. 2002;132:217-229.

15. Pascaretti-Grizon F, Libouban H, Camprasse G, Camprasse S, Mallet R, Chappard D. The interface between nacre and bone after implantation in the sheep: a nanotomographic and Raman study. J Raman Spectrosc. 2014;45:558-564.

16. Hamza S, Slimane N, Azari Z, Pluvinage G. Structural and mechanical properties of the coral and nacre and the potentiality of their use as bone substitutes. Appl Surface Sci. 2012;264:485-491.

17. Berland S, Delattre O, Borzeix S, Catonne Y, Lopez E. Nacre/bone interface changes in durable nacre endosseous implants in sheep. Biomaterials. 2005;26:2767-2773. 
18. Duplat $D$, Chabadel A, Gallet $M$, et al. The in vitro osteoclastic degradation of nacre. Biomaterials. 2007;28:2155-2162.

19. Lamghari M, Berland S, Laurent A, Huet H, Lopez E. Bone reactions to nacre injected percutaneously into the vertebrae of sheep. Biomaterials. 2001;22:555-562.

20. Sweedy A, Bohner M, van Lenthe GH, Baroud G. A novel method for segmenting and aligning the pre- and post-implantation scaffolds of resorbable calcium-phosphate bone substitutes. Acta Biomater. 2017; 54:441-453.

21. Dempster DW, Compston JE, Drezner MK, et al. Standardized nomenclature, symbols, and units for bone histomorphometry: a 2012 update of the report of the ASBMR histomorphometry nomenclature committee. J Bone Mineral Res. 2013;28:2-17.

22. Chappard D. Technical Aspects: How do we Best Prepare Bone Samples for Proper Histological Analysis? Bone Cancer. 2nd ed. Paris: Elsevier; 2015:111-120.

23. Atlan G, Delattre $\mathrm{O}$, Berland $\mathrm{S}$, et al. Interface between bone and nacre implants in sheep. Biomaterials. 1999;20:1017-1022.

24. Liao H, Mutvei H, Sjöström M, Hammarström L, Li J. Tissue responses to natural aragonite (Margaritifera shell) implants in vivo. Biomaterials. 2000;21:457-468.

25. Alexander KA, Raggatt $\mathrm{L}$, Millard S, et al. Resting and injury-induced inflamed periosteum contain multiple macrophage subsets that are located at sites of bone growth and regeneration. Immunol Cell Biol. 2017;95:7-16.

26. Batoon L, Millard SM, Wullschleger ME, et al. CD169+ macrophages are critical for osteoblast maintenance and promote intramembranous and endochondral ossification during bone repair. Biomaterials. 2019; 196:51-66.

27. Bozec A, Soulat D. Latest perspectives on macrophages in bone homeostasis. Pflügers Archives Eur J Physiol. 2017;469:517-525.

28. Chang MK, Raggatt L-J, Alexander KA, et al. Osteal tissue macrophages are intercalated throughout human and mouse bone lining tissues and regulate osteoblast function in vitro and in vivo. J Immunol. 2008;181:1232-1244.
29. Rubin CT, Bain SD, McLeod KJ. Suppression of the osteogenic response in the aging skeleton. Calcified Tissue Int. 1992;50:306-313.

30. Courpron P, Meunier P, Edouard C, Bernard J, Bringuier JP, Vignon G. Quantitative histological data on the aging of human bone. Revue du Rhumatisme et Des Maladies Osteo-Articulaires. 1973;40:469-483.

31. Lu H, Cui L, Zuo C, Lin S, Wu T. Evaluation of morphological parameters of bone formation in Sprague-Dawley rats of different ages by in vivo fluorochrome labeling. Ital J Zool. 2015;82:33-40.

32. Rony L, Aguado E, Pascaretti-Grizon F, Hubert L, Chappard D. Hyaluronic acid stimulates osseointegration of $\beta$-TCP in young and old ewes. Calcified Tissue Int. 2019;105:487-496.

33. Barthelat F, Li C-M, Comi C, Espinosa HD. Mechanical properties of nacre constituents and their impact on mechanical performance. J Mater Res. 2006;21:1977-1986.

34. Liaqat F, Tahir MN, Schechtel E, et al. High-performance TiO2 nanoparticle/DOPA-polymer composites. Macromol Rapid Commun. 2015;36:1129-1137.

35. Song F, Soh A, Bai Y. Structural and mechanical properties of the organic matrix layers of nacre. Biomaterials. 2003;24:3623-3631.

36. Gopalan $\mathrm{H}$, Chokshi $\mathrm{AH}$. The mechanical behavior of nacre across length scales. J Mech Behav Biomed Mater. 2018;78:96-107.

37. Pascual D, Roig R, Chossegros C. Bone graft reconstruction for posterior mandibular segment using the formwork technique. Stomatologie Chirurgie Maxillo-Faciale et de Chirurgie Orale. 2014;115:105-110. 